\title{
LC-MS methods for trace determination of pesticides in environmental samples
}

\author{
I. Ferrer and D. Barceló
}

Dpt. Environmental Chemistry, CID-CSIC clo Jordi Girona, 18-26, 08034 Barcelona, Spain

\begin{abstract}
An important advance for the trace determination of pesticides in real samples has been achieved by the use of highly sensitive techniques such as Liquid Chromatography-Mass Spectrometry (LC-MS). On the other hand, the combination of a trace enrichment procedure such as solidphase extraction (SPE) together with LC-MS improves the analyte detectability at the low ppt level of concentration, often required in environmental analysis. Several interfaces have been widely applied for the determination of many pesticides in environmental samples. In this overview, applicability of some interfaces such as Particle Beam (PB), Atmospheric Pressure Chemical Ionization (APCI) and Electrospray (ESP), is given in terms of sensitivity, structural information and type of compounds to be analyzed. Examples on the trace determination of pesticides in natural waters and sediment samples will be presented. Finally, recommendations about the most appropriate interfaces for each pesticide group are given.
\end{abstract}

A wide range of analytical techniques has been developed in order to identify organic contaminants often present at trace levels in environmental samples. These techniques account mainly for Gas Chromatography (GC) and High Performance Liquid Chromatography (HPLC). Since polar, non-volatile, thermally unstable or high-molecular-weight compounds are unsuitable for Gas Chromatography-Mass Spectrometry (GC-MS) analysis, the use of LC-MS has become a robust and routinely applicable tool in environmental laboratories [1-3]. The performance of LC-MS to analyze polar and thermally labile pesticides that are not amenable for GC-MS is well demonstrated in several studies [4,5].

The initial incompatibility between LC and MS has been solved by different interfaces. The development of thermospray (TSP) and particle beam (PB) overcame some of the initial interface shortcomings allowing the analysis of chlorinated phenoxyacid herbicides, azo dyes, nitroso compounds, and organophosphorus pesticides [6]. Although TSP has been widely used in many applications, its main disadvantage is the lack of structural information for the confirmation of unknown compounds. Thermospray spectra often fail to provide sufficient fragmentation for compound confirmation. On the other hand, PB is useful for identifying unknown compounds although it cannot ionize non-volatile compounds and does not offer enough sensitivity for ppt level determinations. Moreover, the linearity of the response and the sensitivity using PB is limited at trace levels of concentration.

The US EPA has published two methods involving PB [7,8] and one involving TSP [9]. Method 553 involves the extraction of $1 \mathrm{~L}$ of water sample by liquid-liquid extraction (LLE) with dichloromethane or solid-phase extraction (SPE) followed by LC-PB-MS. Similarly, method 8325 also uses PB-MS but in this case the method is applied to waste water matrices. In this method it is indicated that the limits of detection (LOD's) are compound and matrix dependent. In this sense, LC-PB-MS has been implemented by the US EPA especially for the possibility of identifying unknown analytes in complex waste water samples using the power of electron impact (EI) spectra. The comparison of two US EPA methods, one using GC-ECD and the other one using LC-PB-MS was carried out for the determination of various acidic chlorinated acids in water [10]. An advantage of LCMS over GC-ECD was noticed in the determination of 4nitrophenol and 3,5-dichlorobenzoic acid, which offered derivatization problems under the current US EPA method. The last method released by the US EPA involving LC-MS incorporates a TSP interface [9]. This method is applicable to the determination of a wide range of analytes, including dyes, organophosphorus pesticides, chlorinated acids and carbamates in waste water, ground water and soil/sediment matrices.

In the last few years, interfaces based on atmospheric pressure ionization (API) have experimented an increase in the number of applications for environmental determinations. In this respect, Atmospheric Pressure Chemical Ionization (APCI) has recently become the most universal technique for environmental analysis due to the high sensitivity, the possibility of detecting a broad range of analytes and the useful structural information obtained via fragmentation similar to collision induced dissociation (CID) [11-13]. Compared with TSP and PB, APCI offers both structural confirmation and high sensitivity for target compounds in environmental samples. The types of API interfaces available are: APCI, Electrospray (ESP) and HighFlow Pneumatically Assisted Electrospray or Ion Spray (ISP). The major differences between the last two interfaces, for routine pesticide analysis, is that in conventional ESP only $20-50 \mu \mathrm{L} / \mathrm{min}$ are directed to the MS source, so it is necessary to split the LC-flow, whereas in ISP up to $0.3-$ $0.4 \mathrm{~mL} / \mathrm{min}$ can be handled by the ISP interface, with no need for splitting the LC eluent. Both type of interfaces provide an ionization of the molecules, caused mainly by ion evaporation (around 90\%), with a sensitivity sufficient for

* To whom correspondence should be addressed. 
the trace analysis of pesticides in natural waters, where concentrations are frequently below the $\mu \mathrm{g} / \mathrm{L}$ level. This interface is very useful for polar and thermally labile compounds; on the other hand, semipolar analytes are not easily ionized by this type of interface. One of the great advantages of the ESP interface is its high sensitivity for ionic pesticides such as many herbicide metabolites containing a sulfonic or a carboxylic group in the chemical structure $[14,15]$.

\section{Sample handling}

Since many pesticides present in environmental samples, such as water and sediments, are present at low concentration levels it is necessary to carry out a previous step for their enrichment before their LC-MS determination. In this sense, sample preconcentration is necessary in order to reach the low detection limits required in environmental analysis.

As regards the SPE of pesticides from water samples, there exists several automated sample preparation stations, which decrease the time and cost of sample preparation. There are two different types of trace enrichment methodologies: off-line and on-line procedures. In an off-line methodology one aliquot of the extract containing the pesticides is injected into the liquid chromatograph whereas in an on-line methodology the entire fraction of the sample retained in the cartridge is analyzed, thus leading to less manipulation of the sample and higher sensitivity [16]. The concept of this system is that a sample is being pumped and processed onto the SPE cartridge while the liquid chromatograph is processing the preceding sample. The SPE cartridge is then eluted directly onto the HPLC column, increasing the detection limit of the entire method.

There are a wide variety of solid-phase extraction sorbents such as $\mathrm{C}_{18}$ or polymeric ones that are suitable for the determination of pesticides at the $0.1 \mu \mathrm{g} / \mathrm{L}$ level in drinking water (required by the Drinking Water Directive of the Commission of European Community, DWD-CEC) [17]. Recently, immunoaffinity sorbents have been developed for the selective trace pre-concentration of triazine and phenylurea herbicides from environmental samples [18]. Immunosorbents are constituted of polyclonal or monoclonal antibodies covalently bound to a silica sorbent. Taking advantage of the cross-reactivity of a specific antibody it is possible to extract many compounds of the same family. In this sense, the antibodies can recognize the antigen and other compounds with similar structures, thus increasing the selectivity of the preconcentration step.

\section{$\mathrm{APCl}$ vs. PB}

A comparison between APCI and PB in both positive and negative modes of operation was carried out for the determination of a variety of pesticides of different chemical nature [19]. An automated SPE device, OSP-2, was connected on-line with the gradient pumps of the HPLC-MS system. Water samples were pre-concentrated on disposable pre-columns (Merck) prepacked with $10 \mu \mathrm{m}$ LiChrospher Si100 RP-18 and further analyzed by APCI-MS and PBMS.
Tables I and II show the major ions obtained after the analysis by APCI-MS under positive and negative acquisition mode and after the analysis by PB-MS under electron impact mode respectively. As it can be observed in table I, mass spectra for the triazines and phenylureas obtained under APCI conditions showed molecular mass information but little fragmentation was observed. However, it is possible to increase the degree of fragmentation by increasing the cone voltage although a decrease on sensitivity is noticed and no molecular mass information is obtained under those conditions. For triazine and phenylurea herbicides the sensitivity was higher under positive ion mode than in negative ion mode of operation. On the other hand, for organophosphorus pesticides an important fragmentation was achieved after their analysis by APCI-MS. Moreover, the sensitivity encountered for these compounds was higher in negative ion mode than in positive ion mode as previously reported [20]. As shown in table II, an important fragmentation was obtained after the analysis by PB-MS under electron impact ionization as compared with the results obtained by APCI. In general, EI provides more structural informative spectra than APCI, except for organophosphorus pesticides for which in APCI spectra different ions appear. The advantage of using EI is that it generates library searchable spectra and thus it is helpful for analyte identification.

From the results obtained comparing PB and APCI, it can be pointed out that when using PB a better identification of unknown compounds can be obtained due to the availability of EI library searchable spectra. On the other hand, APCI is a very valuable technique due to its higher sensitivity as compared with PB and also a good structural information can be obtained after the optimization of some parameters such as the cone voltage.

In figure 1 typical chromatograms obtained after the percolation, on a $\mathrm{C}_{18}$ cartridge, of $200-\mathrm{mL}$ of tap water sample spiked at $0.04 \mu \mathrm{g} / \mathrm{L}$ level under APCI using Time-Schedule Selected Ion Monitoring (SIM) conditions in positive and negative acquisition modes are shown. In comparison with PB, APCI was shown to be much more sensitive in terms of detection limits and with a higher linear range.

\section{ESP vs. APCI}

Chloroacetanilide herbicides, acetochlor, alachlor and metolachlor are known to degrade more quickly in soil than triazine herbicides. So that, the occurrence of chloroacetanilide metabolites in surface water and groundwater is a common fact [21]. Moreover, studies of metabolites of parent herbicides are critical to understanding the fate and transport of herbicides applied to soil. For these reasons, continued development of reliable and sensitive methods of analysis for metabolites are very important. One relatively new method of analysis of ionic metabolites in water is the use of LC-MS by means of ISP ionization. Since Electrospray ionization occurs by means of ion evaporation from the liquid phase, it is expected that those compounds already in ionic form in solution can be detected with a high sensitivity using this type of interface. According to this, a new analytical method was recently developed for the analysis of the oxanilic and sulfonic acids of the chloroacetanilide herbicides in surface and groundwater samples [15]. These 
Table I. Important mass spectral fragments and their relative abundances obtained by LC-APCI/MS under positive and negative mode of acquisition [19].

\begin{tabular}{|c|c|c|c|c|c|}
\hline Compound & $M_{w}$ & $\begin{array}{c}\mathrm{PCl} \\
\mathrm{m} / \mathrm{z} \text { and tentative ions }\end{array}$ & $R A(\%)$ & $\begin{array}{c}\mathrm{NCl} \\
\mathrm{m} / \mathrm{z} \text { and tentative ions }\end{array}$ & $R A(\%)$ \\
\hline Ametryn & 227 & $228[\mathrm{M}+\mathrm{H}]^{+}$ & 100 & n.d. . & \\
\hline Atrazine & 215 & $216[\mathrm{M}+\mathrm{H}]^{+}$ & 100 & n.d. & \\
\hline Prometryn & 241 & $242[\mathrm{M}+\mathrm{H}]^{+}$ & 100 & n.d. & \\
\hline Bentazone & 240 & $\begin{array}{c}120\left[\mathrm{C}_{6} \mathrm{H}_{4} \mathrm{NH}_{2} \mathrm{CO}\right]^{+} \\
241[\mathrm{M}+\mathrm{H}]^{+}\end{array}$ & $\begin{array}{c}100 \\
20\end{array}$ & $239\left[^{\mathrm{M}}-\mathrm{H}\right]^{-}$ & 100 \\
\hline Fenitrothion & 277 & $\begin{array}{c}248[\mathrm{M}-\mathrm{NO}+\mathrm{H}]^{+} \\
124\left[\mathrm{PS}\left(\mathrm{OCH}_{3}\right)_{2}-\mathrm{H}\right]^{+} \\
262\left[\mathrm{M}-\mathrm{CH}_{3}\right]^{+}\end{array}$ & $\begin{array}{l}100 \\
95 \\
20\end{array}$ & $\begin{array}{c}152\left[\mathrm{C}_{6} \mathrm{H}_{3} \mathrm{ONO}_{2} \mathrm{CH}_{3}\right]^{-} \\
168\left[\mathrm{SC}_{6} \mathrm{H}_{3} \mathrm{NO}_{2} \mathrm{CH}_{3}\right]^{-} \\
262\left[\mathrm{M}-\mathrm{CH}_{3}\right]^{-}\end{array}$ & $\begin{array}{l}100 \\
50 \\
40\end{array}$ \\
\hline Parathion-ethyl & 291 & $\begin{array}{c}262\left[\mathrm{M}-\mathrm{C}_{2} \mathrm{H}_{5}\right]^{+} \\
110\left[\left(\mathrm{CH}_{3} \mathrm{O}\right)_{2} \mathrm{POH}\right]^{+} \\
234\left[\mathrm{M}-\left(\mathrm{C}_{2} \mathrm{H}_{5}\right)_{2}\right]^{+} \\
276\left[\mathrm{M}-\mathrm{CH}_{3}\right]^{+}\end{array}$ & $\begin{array}{l}100 \\
80 \\
45 \\
30\end{array}$ & $\begin{array}{c}138\left[\mathrm{O}_{2} \mathrm{NC}_{6} \mathrm{H}_{4} \mathrm{O}\right]^{-} \\
154\left[\left(\mathrm{C}_{2} \mathrm{H}_{5} \mathrm{O}\right)_{2} \mathrm{PSH}\right]^{-} \\
169\left[\left(\mathrm{C}_{2} \mathrm{H}_{5} \mathrm{O}\right)_{2} \mathrm{POS}\right]^{-} \\
262\left[\mathrm{M}-\mathrm{CH}_{2} \mathrm{CH}_{3}\right]^{-} \\
122\left[\mathrm{C}_{6} \mathrm{H}_{4} \mathrm{NO}_{2}\right]^{-}\end{array}$ & $\begin{array}{l}100 \\
50 \\
40 \\
20 \\
15\end{array}$ \\
\hline Malathion & 330 & $\begin{array}{c}285\left[\mathrm{M}-\mathrm{C}_{2} \mathrm{H}_{5} \mathrm{O}\right]^{+} \\
\left.127\left[\mathrm{M}-\left(\mathrm{CH}_{3} \mathrm{O}\right)_{2} \mathrm{PS} \mathrm{S}_{2}\right)-\left(\mathrm{C}_{2} \mathrm{H}_{6} \mathrm{O}\right)\right]^{+} \\
353[\mathrm{M}+\mathrm{Na}]^{+} \\
331[\mathrm{M}+\mathrm{H}]^{+}\end{array}$ & & $157\left[\left(\mathrm{CH}_{3} \mathrm{O}_{2}\right) \mathrm{PS}_{2}\right]^{-}$ & 157 \\
\hline Isoproturon & 206 & $\begin{array}{c}207[\mathrm{M}+\mathrm{H}]^{+} \\
229[\mathrm{M}+\mathrm{Na}]^{+}\end{array}$ & $\begin{array}{c}100 \\
25\end{array}$ & $205[\mathrm{M}-\mathrm{H}]^{-}$ & 100 \\
\hline MCPA & 200 & n.d. & & $199[\mathrm{M}-\mathrm{H}]^{-}$ & 100 \\
\hline 4-nitrophenol & 139 & n.d. & & $138[\mathrm{M}-\mathrm{H}]^{-}$ & 100 \\
\hline
\end{tabular}

* n.d.: no spectra detected under experimental conditions.

Table II. Important mass spectral fragments and their relative abundances obtained by LC-PB-MS under electron impact ionization [19].

\begin{tabular}{|c|c|c|c|}
\hline \multirow[t]{2}{*}{ Compound } & \multirow[t]{2}{*}{$M_{w}$} & \multicolumn{2}{|l|}{ El } \\
\hline & & $\mathrm{m} / \mathrm{z}$ and tentative ions & $R A(\%)$ \\
\hline \multirow[t]{3}{*}{ Ametryn } & 227 & $228[\mathrm{M}]^{+}$ & 100 \\
\hline & & $212\left[\mathrm{M}-\mathrm{CH}_{3}\right]^{+}$ & 50 \\
\hline & & $170\left[\mathrm{M}-\mathrm{C}_{3} \mathrm{H}_{8} \mathrm{NH}\right]^{+}$ & 35 \\
\hline \multirow[t]{2}{*}{ Atrazine } & 215 & $200\left[\mathrm{M}-\mathrm{CH}_{3}\right]^{+}$ & 100 \\
\hline & & $216[\mathrm{M}+\mathrm{H}]^{+}$ & 60 \\
\hline \multirow[t]{3}{*}{ Prometryn } & 241 & $226\left[\mathrm{M}-\mathrm{CH}_{3}\right]^{+}$ & 100 \\
\hline & & $184\left[\mathrm{M}-\mathrm{NCH}\left(\mathrm{CH}_{3}\right)_{2}\right]^{+}$ & 95 \\
\hline & & $241[\mathrm{M}]^{+}$ & 65 \\
\hline Bentazone & 240 & $120\left[\mathrm{C}_{6} \mathrm{H}_{4} \mathrm{NH}_{2} \mathrm{CO}\right]^{+}$ & 100 \\
\hline \multirow[t]{3}{*}{ Fenitrothion } & 277 & $138\left[\mathrm{O}_{2} \mathrm{NC}_{6} \mathrm{H}_{4} \mathrm{O}\right]^{+}$ & 100 \\
\hline & & $248[\mathrm{M}-\mathrm{NO}]^{+}$ & 70 \\
\hline & & $277\left[\mathrm{M}^{+}\right.$ & 30 \\
\hline \multirow[t]{2}{*}{ Parathion-ethyl } & 291 & $109\left[\mathrm{C}_{2} \mathrm{H}_{5} \mathrm{OP}_{2} \mathrm{H}\right]^{+}$ & 100 \\
\hline & & $291[\mathrm{M}]^{+}$ & 55 \\
\hline \multirow[t]{2}{*}{ Malathion } & 330 & $\left.173\left[\mathrm{M}-\left(\mathrm{CH}_{3} \mathrm{O}\right)_{2} \mathrm{PS}_{2}\right)\right]^{+}$ & 100 \\
\hline & & $\begin{array}{c}127\left[\mathrm{M}-\left(\mathrm{CH}_{3} \mathrm{O}\right)_{2} \mathrm{PS}_{2}\right)- \\
\left.\left(\mathrm{C}_{2} \mathrm{H}_{6} \mathrm{O}\right)\right]^{+}\end{array}$ & 90 \\
\hline \multirow[t]{2}{*}{ Isoproturon } & 206 & $72\left[\left(\mathrm{CH}_{3}\right)_{2} \mathrm{NCO}\right]^{+}$ & 100 \\
\hline & & $206[\mathrm{M}]^{+}$ & 35 \\
\hline \multirow[t]{2}{*}{ MCPA } & 200 & $141\left[\mathrm{M}-\mathrm{CH}_{2} \mathrm{COOH}\right]^{+}$ & 100 \\
\hline & & $200[\mathrm{M}]^{+}$ & 65 \\
\hline \multirow[t]{2}{*}{ 4-nitrophenol } & 139 & $109[\mathrm{M}-\mathrm{NO}]^{+}$ & 100 \\
\hline & & $139[\mathrm{M}]^{+}$ & 40 \\
\hline
\end{tabular}

metabolites could be measured with great sensitivity with detection levels of $0.01 \mu \mathrm{g} / \mathrm{L}$ for a $100-\mathrm{mL}$ water sample and this study represented the first confirmation of these metabolites in environmental waters of the Midwestern United States using LC-MS.

Di Corcia et al. [22] showed the applicability of the ESP interface for the determination of several metabolites of atrazine at the sub ppt level of concentration in river water samples. In this work, limits of detection ranging from 0.03 to $0.14 \mathrm{ng}$ for atrazine and its six major degradation products in environmental waters were achieved.

Immunosorbents coupled on-line to LC-MS were applied to the trace determination of several triazine and phenylurea herbicides in sediment and water samples [23]. By this approach, a selective extraction method using immunosorbents for the preconcentration of the samples can be combined with a highly sensitive detection system such as LCAPCI-MS with selected ion monitoring. This methodology allows for the determination of organic pollutants at the low nanogram per liter level using small preconcentration sample volumes. Triazine and phenylurea herbicides do not present a major fragmentation under APCI conditions although the molecular mass information and the sensitivity obtained are sufficient for trace level determinations in environmental samples using this type of interface. In figure 2 a typical chromatogram obtained after the analysis of a $20-\mathrm{mL}$ of water containing the extract of a sediment sample by LCAPCI-MS in positive ion mode of operation is shown. As it can be seen in this figure, the chromatogram obtained under 


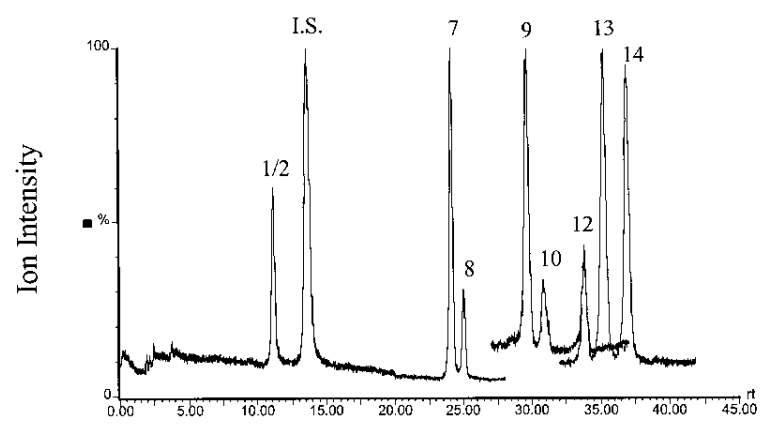

Time (minutes)

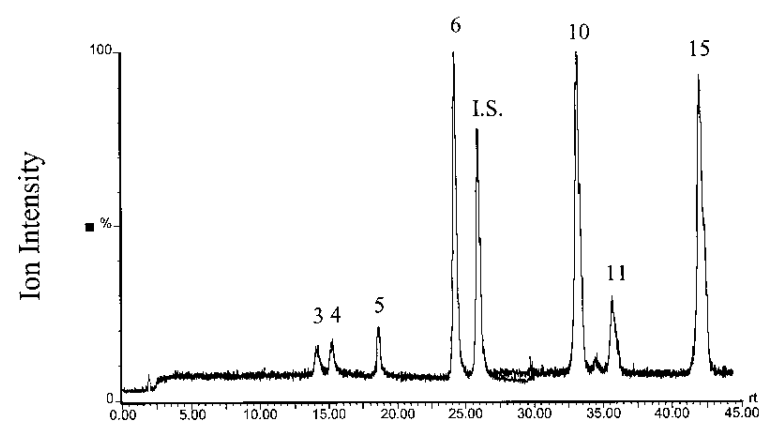

Time (minutes)

Figure 1. Chromatogram obtained by on-line SPE-LC-APCI-MS of $200 \mathrm{~mL}$ of tap water spiked at $0.04 \mu \mathrm{g} / \mathrm{L}$ of pesticides under PI mode and Time-Schedule SIM a) and using NI ionization mode b). Peak numbers: 1 = bentazone, 2 = vamidothion, $3=4$ nitrophenol, 4 = MCPA, 5 = mecoprop, 6 = dinoseb, 7 = atrazine, $\mathbf{8}$ = isoproturon, $\mathbf{9}=$ ametryn, 10 = malathion, 11 = fenitrothion, 12 = molinate, 13 = prometryn, 14 = terbutryn, 15 = parathionethyl and I.S. = internal standard.

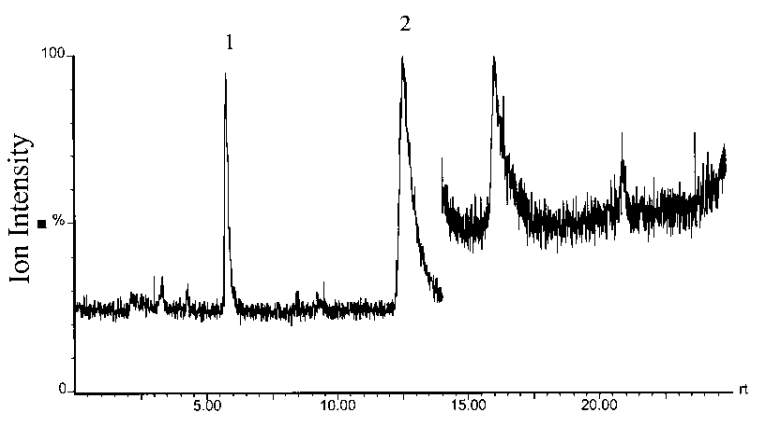

Time (minutes)

Figure 2. On-line solid-phase extraction of $20 \mathrm{~mL}$ of water containing the extract of a sediment sample through an antiatrazine immunosorbent followed by LC/APCI/MS in Positive lon (PI) mode of operation and under Time-Schedule SIM-PI conditions. Analytical conditions as described in [23]. Peak numbers: 1 = deethylatrazine; 2 = atrazine + deuterated atrazine.

these conditions presented a clear baseline and the compounds could be easily identified and detected.

\section{General recommendations}

In table III the limits of detection obtained using different interfaces are compared. In general terms, LC-APCI-MS and LC-ESP-MS are the most sensitive detection methods for the analysis of polar pesticides in environmental samples. Moreover, the robustness of these techniques is superior to TSP or PB interfaces as it has been discussed before.

Finally, in table IV it is summarized the capabilities of APCI and ESP or ISP for the determination of various pesticide groups. As it can be seen in this table, polar pesticides or molecules with an acidic or basic site are best detected using an ion evaporation ionization process by means of electrospray whereas less polar compounds can be best addressed using an APCI interface.

\section{Conclusions}

LC-MS is the preferred technique for the identification and quantification of polar and thermally labile compounds that are not GC amenable. Thermospray interface has been widely used but it is not very useful for the identification of

Table III. Comparison of LOD's (ng) for a variety of pesticides using different types of interfaces under SIM conditions [3, 14, 15, 19, 20, 23].

\begin{tabular}{|c|c|c|c|c|}
\hline Compound & $\begin{array}{c}\text { HPLC- } \\
\text { UV }\end{array}$ & $\begin{array}{c}L C- \\
P B-M S\end{array}$ & $\begin{array}{c}L C- \\
A P C I-M S\end{array}$ & $\begin{array}{l}\text { LC-ESP/ } \\
\text { ISP-MS }\end{array}$ \\
\hline Fenitrothion & 5 & 10 & 0.2 & n.d. \\
\hline Malathion & 10 & 4 & 0.3 & n.d. \\
\hline Parathion-ethyl & 5 & 10 & 0.6 & n.d. \\
\hline Atrazine & 0.5 & 4 & 0.2 & 0.4 \\
\hline Terbuthylazine & 0.5 & 3 & 0.4 & 0.5 \\
\hline Isoproturon & 1 & 4 & 0.4 & 0.1 \\
\hline Diuron & 1 & 4 & 0.5 & 0.2 \\
\hline Molinate & 10 & n.d. & 0.2 & n.d. \\
\hline 4-nitrophenol & 1 & n.d. & 0.1 & 1 \\
\hline Bentazone & 5 & n.d. & 0.8 & 0.5 \\
\hline $2,4-D$ & 10 & n.d. & n.d. & 1 \\
\hline
\end{tabular}

n.d. not determined.

Table IV. General recommendations for different groups of pesticides.

\begin{tabular}{lcc}
\hline Pesticide group & APCI & ESP/ISP \\
\hline Organophosphorus & $\mathrm{x}$ & \\
Triazines & $\mathrm{x}$ & $\mathrm{x}$ \\
Phenols & $\mathrm{x}$ & \\
Phenylureas & $\mathrm{x}$ & $\mathrm{x}$ \\
Acidic pesticides & & $\mathrm{x}$ \\
\hline
\end{tabular}


unknown compounds due to its lack of structural information. On the other hand, Particle Beam and Atmospheric Pressure Chemical Ionization interfaces provide sufficient fragmentation for identification of unknown compounds in environmental samples. In this sense, many compounds give similar spectra for PB and APCI whereas for some other compounds such as organophosphorus pesticides, different spectra are obtained. In general, with the APCI interface a greater number of compounds may be determined than with the PB interface. Moreover, the linearity and sensitivity is better using the APCI interface. Finally, the Electrospray interface is a very useful technique for the analysis of ionic metabolites of parent compounds such as triazine and chloroacetanilide herbicides showing a high sensitivity for the determination of traces of pesticides in environmental samples.

\section{Acknowledgments}

This work has been supported by the Commission of the European Communities, Environment and Climate Program (Contract ENV4-CT95-0066) and (Contract ENV4-CT970384) PLANCICYT (AMB96-2808-CE).

\section{References}

1. Niessen, W. M. A.; Tinke, A. P; J. Chromatogr. A 1995, 703, 37.

2. Slobodnik, J.; van Baar, B. L. M.; Brinkman, U. A. Th. J. Chromatogr. A 1995, 703, 81.

3. Molina, C.; Honing, M.; Barceló, D. Anal. Chem. 1994, 66, 4444-4449.

4. Barceló, D. in: Application of LC-MS in Environmental Chemistry, J. Chromatogr. Library, Elsevier, Amsterdam, 1996, Vol. 59.

5. Grosser, Z. A.; Ryan, J. F.; Dong, M. W; J. Chromatogr. 1993, $642,75-87$
6. Behymer, T.; Bellar, T. A.; Budde, W. L. Anal. Chem. 1990, 62, 1686-1690.

7. US EPA Method 553. Determination of benzidines and nitrogen-containing pesticides in water by LLE or LSE and reverse phase HPLC-PB-MS, August 1992, Environmental Monitoring systems laboratory, US EPA, Cincinnati, OH 45268.

8. US EPA Method 8325. Solvent extractable non-volatile compounds by HPLC-PB-MS or UV detection, US EPA Office of Solid Waste and Emergency Response, Washington, DC, 1995 ; pp 1-50.

9. US EPA Method 8321 A. Solvent extractable non-volatile compounds by HPLC-TSP-MS or UV detection, US EPA Office of Solid Waste and Emergency Response, Washington, DC, 1995 ; pp 1-50.

10. Bruner, F.; Berloni, A.; Palma, P. Chromatographia 1996, 43, 279.

11. Galcerán, M. T.; Moyano, E. J. Chromatogr. A 1996, 731, 75.

12. Bruins, A. P. Trends Anal. Chem. 1994, 13, 37.

13. Slobodnik, J.; Hogenboom, A. C.; Vreuls, J. J.; Rontree, J. A.; van Baar, B. L. M.; Niessen, W. M. A.; Brinkman, U. A. Th. J. Chromatogr. A 1996, 741, 59.

14. Chiron, S.; Papilloud, S.; Haerdi, W.; Barceló, D. Anal. Chem. 1995, 67, 1637-1643.

15. Ferrer, I.; Thurman, E. M.; Barceló, D. Anal. Chem. 1997, 69, 4547-4553.

16. Barceló, D.; Hennion, M. -C. Anal. Chim. Acta 1995, 318, 1.

17. Slobodnik, J.; Brouwer, E. R.; Geerdink, R. B.; Mulder, W. H.; Lingeman, H.; Brinkman, U. A. Th. Anal. Chim. Acta 1992, 268, 55-65.

18. Pichon, V.; Chen, L.; Hennion, M. -C.; Daniel, R.; Martel, A.; Le Goffic, F.; Abian, J.; Barceló, D. Anal. Chem. 1995, 67, 2451.

19. Aguilar, C.; Ferrer, I.; Borrull, F.; Marcé, R. M.; Barceló, D. J. Chromatogr. A 1998, 794, 147..

20. Lacorte, S.; Barceló, D. Anal. Chem. 1996, 68, 2464-2470.

21. Thurman, E. M.; Goolsby, D. A.; Aga, D. S.; Pomes, M. L.; Meyer, M. T. Environ. Sci. Technol. 1996, 30, 569-574.

22. Di Corcia, A.; Crescenzi, C.; Guerriero, E.; Samperi, R. Environ. Sci. Technol. 1997, 31, 1658-1663.

23. Ferrer, I.; Hennion, M. -C.; Barceló, D. Anal. Chem. 1997, 69, 4508-4514. 